Energyplexes for the 21st Century: Coal Gasification for Coproducing Hydrogen, Electricity and Liquid Fuels

Kei Yamashita and Leonardo Barreto

RP-05-005

June 2005

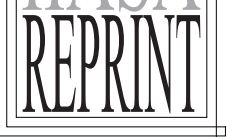





\section{Energyplexes for the 21st Century: Coal Gasification for Co-producing Hydrogen, Electricity and Liquid Fuels}

Kei Yamashita

Tokyo Electric Power Company, Tokyo, Japan

Leonardo Barreto

International Institute for Applied Systems Analysis

Laxenburg, Austria

RP-05-005

June 2005

Reprinted from Energy, 30(13):2453-2473 (2005).

International Institute for Applied Systems Analysis - Schlossplatz 1 - A-2361 Laxenburg • Austria Tel: (+43 2236) 807 • Fax: (+43 2236) 71313 •E-mail: publications@iiasa.ac.at•Web: www.iiasa.ac.at 
IIASA Reprints make research conducted at the International Institute for Applied Systems Analysis more accessible to a wider audience. They reprint independently reviewed articles that have been previously published in journals. Views or opinions expressed herein do not necessarily represent those of the Institute, its National Member Organizations, or other organizations supporting the work.

Reprinted with permission from Energy, 30(13):2453-2473 (2005).

Copyright (C) 2005 Elsevier Ltd.

All rights reserved. No part of this publication may be reproduced or transmitted in any form or by any means, electronic or mechanical, including photocopy, recording, or any information storage or retrieval system, without permission in writing from the copyright holder. 


\title{
Energyplexes for the 21st century: Coal gasification for co-producing hydrogen, electricity and liquid fuels
}

\author{
Kei Yamashita ${ }^{\mathrm{a}, \mathrm{b}}$, Leonardo Barreto ${ }^{\mathrm{b}, *, 1}$ \\ ${ }^{a}$ Tokyo Electric Power Company, 1-3 Uchisaiwai-cho 1 Chome, Chiyoda-ku, Tokyo 100, Japan \\ ${ }^{\mathrm{b}}$ International Institute for Applied Systems Analysis, Schlossplatz 1, Laxenburg A-2361, Austria
}

Received 24 October 2003

\begin{abstract}
This paper illustrates the role that integrated energy systems, also known as 'energyplexes', could play in supplying energy demands in the long term. These systems could enable a multi-fuel, multi-product strategy with both economic and environmental benefits. They could increase the adaptability and robustness of energy-services companies in the marketplace, providing them with flexibility in meeting demands in different market segments while achieving lower production costs and, reducing the risks of reliance on a single feedstock. In addition, with the possibility of achieving high conversion efficiencies and low polluting emissions and facilitating carbon capture, they could deliver high-quality energy services in a cost-effective way while meeting stringent environmental requirements. Their potential is highlighted here using the case of coal-fired, synthesis-gas-based gasification systems that allow co-producing hydrogen, electricity and liquid fuels, i.e. Fischer-Tropsch liquids and methanol, and could be a key building block in a clean-coal technology strategy. Co-production, also known as poly-generation, strategies may contribute to improve the economics of the system and exploit potential synergies between the constituent processes. However, the technical feasibility and economic viability of poly-generation schemes have to be examined carefully on a case-by-case basis.
\end{abstract}

(C) 2005 Elsevier Ltd. All rights reserved.

\section{Introduction}

One promising alternative to fulfill increasingly stringent criteria for providing energy services is the development and deployment of integrated energy conversion and end-use systems. The variety of such

\footnotetext{
* Corresponding author. Tel.: +432236 807 578; fax: +432236 807488 .

E-mail addresses: barreto@iiasa.ac.at (L. Barreto), leonardo.barreto@psi.ch (L. Barreto).

${ }^{1}$ Address: Energy Economics Group, Paul Scherrer Institute, OVGA 122, CH5232 Villigen PSI, Switzerland. Tel.: +41 563 104 142; fax: +41563102624.
} 
integrated systems is large and encompasses a number of options in the industry and energy sectors where processes are flexible, amenable to the inputs of different raw materials, and have the ability of cascading and recycling output products in order to minimize environmental impacts.

In the field of energy conversion, these integrated systems, also known as 'energyplexes', are highly efficient, incorporate advanced technologies that may have fuel flexibility (e.g. coal and biomass) and allow for various combinations of electricity, liquid fuels, hydrogen, chemicals and/or heat [1,2]. Such systems could also allow for an efficient means of separating a number of pollutants and, when using carbon-rich feedstocks, for capturing carbon dioxide. These technologies can become a key option during the course of this century, since they are flexible and able to benefit from potential synergies to produce multiple energy carriers economically and cleanly.

The 'energyplexes' would permit the application of poly-generation strategies. Poly-generation, or co-production, schemes have been highlighted in the literature as promising alternatives for the simultaneous production of electricity, hydrogen, synthetic liquid fuels, heat and/or chemicals [1-5]. Poly-generation schemes may contribute to improve the economic attractiveness of the different products and have the potential to reduce the costs of carbon capture and sequestration. It becomes important to understand the technologies that may enable poly-generation strategies to play a larger role in the global energy system in the long term, the potential benefits they may offer and the barriers their development and deployment could face. Different multi-fuel and/or multi-product energy systems are possible. Here, we examine one of them, namely an integrated energy system based on the production of synthesis gas (syngas) using a coal gasification process and capable of producing, or co-producing, hydrogen, electricity and liquid fuels.

The remainder of this paper is organized as follows. Section 2 highlights the potential role of 'energyplexes' in providing energy services in the long term, emphasizes the importance of clean-coal gasification technologies and presents some considerations on carbon capture in coal-based gasification systems. Section 3 examines a potentially attractive long-term poly-generation strategy, namely the coproduction of hydrogen together with electricity. Section 4 examines two additional poly-generation schemes, involving the co-production of electricity together with clean liquid fuels. The first system involves the co-production of electricity together with the so-called Fischer-Tropsch liquids (i.e. gasoline and diesel produced using the Fischer-Tropsch synthesis process), which could be a near-term co-production scheme. The second scheme illustrates the co-production of electricity and methanol, which could be seen as a medium-term strategy. Finally, Section 5 outlines some conclusions.

\section{Coal gasification for energyplexes}

\subsection{Energyplexes}

The conception and development of multi-product and/or multi-fuel integrated energy systems has been motivated by increasing requirements for market flexibility, security of supply and environmental constraints and by the opportunities for synergies and complementarities between different technologies and energy carriers. Integrated systems capable of using several input feedstocks could be more robust, i.e. less reliant on a single primary-energy source and, consequently, less vulnerable to potential price volatility or resource scarcity. Also, having several products would allow these integrated systems to meet energy needs in different market segments, thus multiplying the possibilities for generating profits 
while achieving lower production costs. In addition, the integrated operation may facilitate the control of pollutants, which would be concentrated in a single facility. With these characteristics, the energyplexes could increase the capability of energy-services companies to compete in traditional and innovative market segments, enhancing their flexibility to react to industry changes and economic uncertainty and helping them to manage risks associated with feedstock supply and market changes and cope with, among others, environmental and financial constraints.

Many efforts are still necessary both on the development of the technologies that operate as building blocks of the 'energyplexes' and of techniques to ensure their compatibility and successful integrated operation. The latter refers, for instance, to approaches that allow adequately integrating modules for feedstock processing, power and synthetic-fuel production and emissions control, in order to materialize the potential for improvements in efficiency, costs and environmental performance resulting from their combination.

Among others, one attractive possibility is that of 'energyplexes' based on the production of synthesis gas (hereon referred to as syngas), a mixture of hydrogen and carbon oxides that can be generated by a variety of processes and feedstocks and can be transformed into a number of chemicals and/or energy carriers. In such systems, syngas operates as the key enabling energy carrier for the multi-fuel and multiproduct strategy. On the one hand, syngas can be obtained from different feedstocks, not only natural gas but also solid feedstocks like coal and biomass, allowing their conversion into higher quality, cleaner and more flexible energy carriers. Moreover, several of these syngas production systems are similar or at least compatible to some extent, thus allowing spillovers of technology learning to occur. These two conditions could facilitate the introduction of multi-fuel systems. On the other hand, syngas allows obtaining a flexible mix of products, electricity, hydrogen, di-methyl-ether, methanol, chemicals, heat, and $\mathrm{CO}_{2}$, facilitating a multi-product strategy.

However, the fact that gasification of solids (e.g. biomass, coal) to synthesis gas is a common feature of syngas-based poly-generation plants does not necessarily mean that future 'energyplexes' will readily accept all inputs and be able to create all products. Surely, some combinations of products would make sense while others do not. In addition, different types of feedstocks will be suitable for different types of products and could have inherent limitations.

Moreover, the technical feasibility and economic viability of poly-generation schemes have to be examined carefully on a case-by-case basis and poly-generation does not necessarily have to result in lower production costs. A critical aspect relates to the assessment of the existence of markets for excess coproducts. As the number of products grows, plant economics becomes increasingly dependent upon the existence of markets for the different products and complex poly-generation arrangements may not be profitable. Moreover, since several products cannot be stored easily, there may be additional risks associated to securing the availability of the plant in order to supply specific product streams. Also, the complexity of the plants may increase the market risks associated with their construction and operation and, thus, could reduce the number of firms willing to make the necessary large investments. In summary, poly-generation facilities do not constitute a 'silver bullet' for the problems associated to novel energy conversion technologies but they may provide promising pathways for specific applications.

\subsection{Clean coal gasification technologies}

Coal continues to be a strategic indigenous primary-energy source in a number of countries and its global reserves and resources are abundant and more evenly distributed than oil or natural gas. 
As such, coal could play an important role in the future global energy system, in particular if security-ofsupply considerations become more pressing. Therefore, it becomes necessary to develop and deploy clean-coal technologies such that the mining, transport, preparation and conversion of coal into higher quality and more convenient energy carriers could be achieved in an efficient and clean manner with minimal environmental impacts. This technology cluster could prevent that more polluting, less efficient coal-based conversion technologies are installed and enhance the possibilities for transforming coal into more convenient final-energy carriers, thus contributing to phase out its direct uses [6,7].

Coal gasification appears as a technology that could be instrumental in achieving the abovementioned goals for clean-coal technologies. The gasification process is a well-established technology that converts a solid feedstock (e.g. coal, biomass) to a synthetic gas (syngas) using steam and an oxidant [8]. The clean syngas can be used directly as town gas or as input for the production of electricity and/or synthetic fuels, e.g. hydrogen, methanol, Fischer-Tropsch (F-T) liquid fuels, among others. Hydrogen can be separated through a gas shifting process that removes carbon dioxide from the syngas. A highly concentrated stream of $\mathrm{CO}_{2}$ can be separated, thus facilitating its capture and storage in case it is needed. In a conventional system, the resulting hydrogen-rich syngas is purified in a pressure swing adsorption (PSA) unit and high-quality hydrogen is obtained.

The coal gasification technology is well suited for the co-production of hydrogen and electricity. Several alternatives are possible, involving different combinations of technologies for hydrogen production, electricity generation and capture of $\mathrm{CO}_{2}$ [9-11]. Co-production could increase the overall efficiency of the process and provide some economic benefits. In general, the mix of both products in such a scheme would depend on their relative prices.

Liquid fuels can be produced by passing the clean syngas through a synthesis process. Different alternatives for production of, among others, methanol, di-methyl-ether (DME) and Fischer-Tropsch (F-T) liquids (diesel, gasoline) are available [5,12]. Syngas-based systems allow for producing liquid fuels with a low content of a number of pollutants. In several system configurations, electricity can be generated as a co-product. Having such a co-production scheme may offer several advantages such as reducing the production costs of the liquid products and facilitating carbon capture (e.g. in the case of F-T liquids or DME), among others [13].

$\mathrm{CO}_{2}$ capture and storage (CCS) could permit the use of carbon-rich primary energy sources while reducing their net carbon emissions to the atmosphere [14]. Hydrogen production from fossil fuels or biomass offers interesting possibilities for carbon capture. Specifically, gasification systems would be well suited since a highly concentrated $\mathrm{CO}_{2}$ stream can be obtained during the process. CCS systems would be a key component of a clean-coal technology strategy. Gasification technologies would facilitate $\mathrm{CO}_{2}$ capture. Although several possibilities for carbon capture in power plants are available $[4,6,15]$, some analyses [16] have suggested that in the long term coal-fired IGCC power plants equipped with pre-combustion capture could have an important role in a carbon-constrained fossil electricity system. Since the same process is used for hydrogen production from coal, the application of precombustion carbon capture approaches for IGCC power plants could make the co-production of hydrogen and electricity an attractive approach. This could pave the way for the introduction of hydrogen as an energy carrier in the long run as a suitable complement to electricity, and for the development and deployment of integrated energy systems.

However, a number of technical, economical, environmental and public-acceptance issues regarding CCS systems are still to be resolved. Carbon capture technologies are currently under development and face a number of challenges. Among others, they must become less energy-intensive and more 
cost-effective, as well as increase the $\mathrm{CO}_{2}$ capture efficiency and be better integrated into the energy conversion plants. Additionally, not less challenging, efforts are required on the long-term storage systems. A better assessment of the storage potential of different reservoirs, their leakage characteristics and associated risks and costs is required. Furthermore, the environmental impacts of both carbon storage and leakage must be quantified and the overall effectiveness of the storage schemes needs to be evaluated and monitored.

\section{Co-production of hydrogen and electricity from coal with $\mathrm{CO}_{2}$ capture}

Hydrogen is a very promising energy carrier for the long term. It can meet a wide range of energy needs in different end-use sectors efficiently and with little or no pollution at the point of use. Hydrogen can be made from a broad portfolio of primary resources, coal among others, having the potential to diversify the energy supply system. Hydrogen production systems can be developed according to the feedstocks available in different regions. This may bring security-of-supply benefits and makes it attractive for facilitating the transition to a sustainable energy system in the long term $[17,18]$.

In the distant future, hydrogen could become an important energy commodity at the global level. Initially, hydrogen could be produced from the current competitive fossil fuels. At a later stage, as the market develops, the production system could evolve towards renewable resources. Although natural gas based hydrogen appears to be the most competitive option today, coal-based hydrogen could be an interesting possibility for those world regions where natural gas is not available or expensive. In addition, new technology innovations could render coal-based hydrogen competitive with gas-based production systems.

Electricity, on the other hand, has become a vital energy carrier in today's world and its importance will certainly increase substantially in the future. The electricity generation, transmission and distribution systems, as well as the institutions and markets associated with them, are evolving and significant structural changes in the global electricity mix and corresponding business models could be expected in the long run. Even so, fossil power plants are bound to continue playing a significant role in meeting the growing world electricity consumption well into the future. This makes necessary the development and deployment of cleaner fossil-based electricity generation technologies. A number of stringent environmental requirements are already imposed on the fossil-fired power plants going on-line today. In the long term, one important not-yet-addressed aspect concerns their carbon emissions. In this respect, gasification technologies may offer an attractive option.

As mentioned above, energyplexes could enable poly-generation strategies. One of the possibilities entails the co-production of hydrogen and electricity. Both are premium-quality, carbon-free, energy carriers with a wide range of applications. They could play preponderant and complementary roles in meeting energy needs in the long term particularly if a low-emissions global energy system is to be reached $[17,18]$. Being 'blind' to their sources, a diversified portfolio of fossil and non-fossil primary resources can be used to produce them. This characteristic makes these two energy carriers attractive for facilitating a transition to a sustainable energy supply system because, while being compatible with the existing structure, they could enable the introduction of carbon-free primary sources and/or facilitate $\mathrm{CO}_{2}$ capture and storage from carbon-intensive sources.

In the long term, attractive opportunities may be created for facilities where hydrogen and electricity are co-produced, in particular if a large-scale 'hydrogen+electricity economy' emerges. 


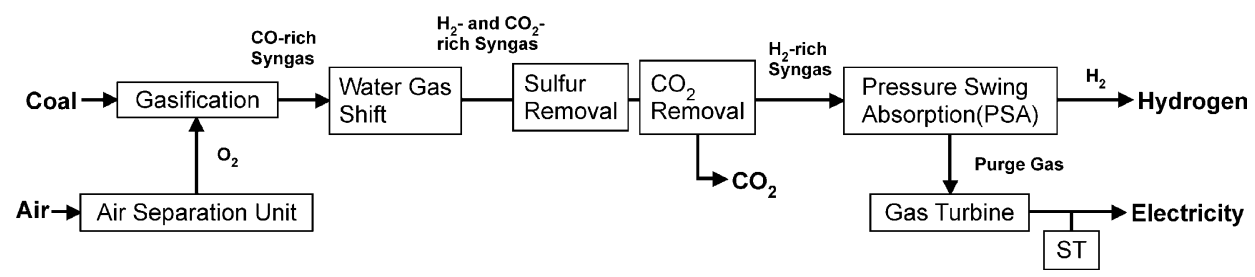

Fig. 1. Co-production of hydrogen and electricity from coal with capture of $\mathrm{CO}_{2}$ using a PSA unit (Case 1).

Co-producing hydrogen and electricity may have several advantages. The efficiency of the integrated process could be higher and capital costs could be reduced. Also, co-production could be a strategy for improving the economics of hydrogen production and stimulate its penetration. Depending on the value at which the co-product electricity can be sold to the network, the hydrogen production costs could be reduced. In addition, centralized co-production plants may facilitate $\mathrm{CO}_{2}$ capture in case it is necessary.

Here, as an illustration, we examine the co-production of hydrogen and electricity by coal gasification for three alternative systems. The first system is a conventional coal gasification process using a Pressure Swing-Adsorption (PSA) unit for hydrogen separation. The two other systems use a membrane-based system for the same purpose. For each system we have examined only the case with carbon capture. Our calculations are based on the techno-economic characteristics reported in [9].

In the first case (Case 1), i.e. the conventional system, the syngas stream from the gasifier is used as input to a shift reactor, from which it passes to a $\mathrm{CO}_{2}$ removal unit and a PSA process from where the hydrogen is recovered. The remaining mix is used as input to a combined-cycle turbine for electricity production (see Fig. 1). For the $\mathrm{CO}_{2}$ removal, a Selexol unit consisting of two absorbers is in place. The first absorbs $\mathrm{H}_{2} \mathrm{~S}$ from the cooled syngas, providing a desulfurized syngas, and the second absorbs $\mathrm{CO}_{2}$ from the desulfurized syngas.

The use of membrane reactors for hydrogen and $\mathrm{CO}_{2}$ separation constitutes an interesting alternative to conventional systems [19,20]. The second co-production system examined here (Case 2) is a membrane-based system (see Fig. 2). Key process components are an $\mathrm{O}_{2}$-blown gasifier, a hydrogen separation membrane reactor (HSMR), and an $\mathrm{O}_{2}$-fired combustor followed by a turbine expander. The hydrogen from the membrane reactor is split into two streams. The first stream corresponds to the hydrogen product and the second stream becomes the input of a hydrogen-fired combined-cycle turbine for electricity generation. Notice that this configuration presupposes that the combined-cycle turbine is able to work with a hydrogen-rich gas efficiently and cleanly. Thus, an adaptation and re-design of current combined-cycle turbines could be required [21].

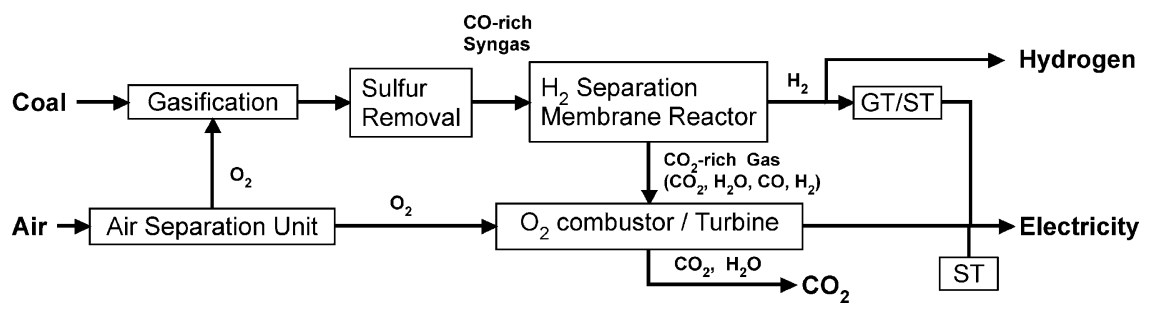

Fig. 2. Co-production of hydrogen and electricity from coal with $\mathrm{CO}_{2}$ capture using a hydrogen separation membrane reactor (Case 2). 


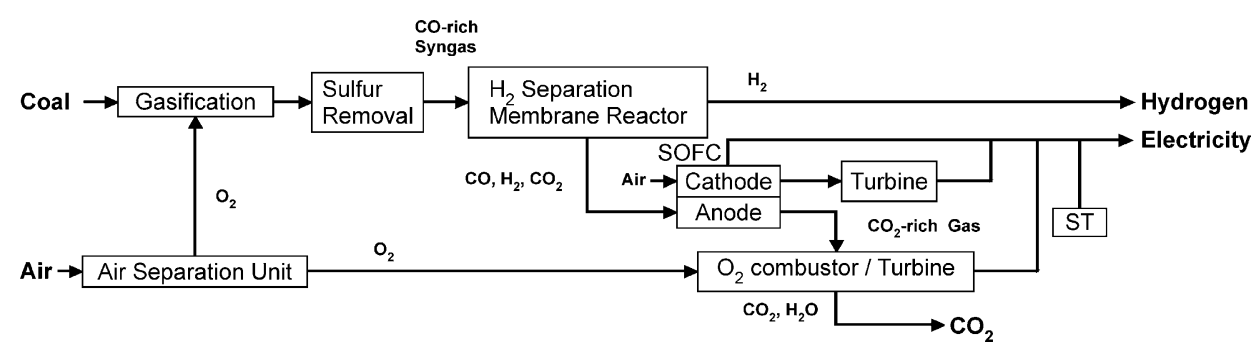

Fig. 3. Co-production of hydrogen and electricity from coal with $\mathrm{CO}_{2}$ capture using a membrane reactor and a Solid Oxide Fuel Cell (SOFC) (Case 3).

The third case for co-production (Case 3) is also a membrane-based system with a Solid Oxide Fuel Cell (SOFC) topping cycle (see Fig. 3). This is a so-called hybrid system that includes the combination of a fuel cell and a gas turbine for electricity generation. It is presented here in order to highlight the possible future potential of such a system, which benefits from synergies between the component technologies to achieve higher conversion efficiencies. The system here is one of the configurations that might have higher efficiencies of electricity generation than Case 1 or Case 2, while the efficiencies of hydrogen production are almost the same.

Membrane-based technologies, however, are at an early R\&D stage and different types of membrane reactors are still being tested. Their introduction as a viable alternative will depend on advances in materials and the development of separation technologies, among others. In particular, it has to be ensured that the membrane systems are able to operate adequately under the difficult conditions (high temperatures and pressures and harsh chemical environments) associated with coal gasification processes and that they can be adequately integrated with other components of the plants. Also, costs of membrane reactors and their future development are much more uncertain than those of other components. Nevertheless, using membrane reactors could allow for the production of hydrogen from syngas at the required purity without a water-gas shift converter or hydrogen purification system.

Using the system configurations described above, we illustrate the effects of the co-production of hydrogen and electricity in the production costs of hydrogen. ${ }^{2}$ Table 1 summarizes the figures for performance and costs used in this analysis, which are derived from [9]. The amount of electricity in the co-production systems ranges between 56 and $83 \%$ of the hydrogen output (Table 1). Notice that the investment cost of Case 3 is based on a SOFC 'stack' cost of US $\$ 400 / \mathrm{kW}$, which can be considered a medium-term target.

For comparison, the characteristics of the hydrogen-only production systems used as reference here are also presented. In these two system configurations examined here, a small amount of electricity is produced and we assume it to be sold to the network. However, the amount is so small that we distinguish these systems from the co-production cases described above.

The first hydrogen-only reference system [1] is a conventional system for hydrogen production from coal using a PSA unit for hydrogen separation. This system is similar to that of Case 1, except that the purge gas is compressed and burned in a steam turbine, instead of a combined-cycle turbine (see Fig. 4).

\footnotetext{
${ }^{2}$ Unless specified otherwise, all monetary values in this paper are expressed in constant 2000 US dollars and all energy values are based on higher heat value (HHV).
} 
Table 1

Summary of co-production systems of hydrogen and electricity from coal and reference hydrogen

\begin{tabular}{lllllll}
\hline & $\begin{array}{l}\text { Hydrogen } \\
\text { capacity (million } \\
\mathrm{Nm}^{3}-\mathrm{H}_{2} / \text { day) }\end{array}$ & $\begin{array}{l}\text { Feedstock ratio } \\
\left(\mathrm{GJ} / \mathrm{GJ}-\mathrm{H}_{2}\right)\end{array}$ & $\begin{array}{l}\text { Electricity } \\
\text { output ratio } \\
\left(\mathrm{GJ} / \mathrm{GJ}-\mathrm{H}_{2}\right)\end{array}$ & $\begin{array}{l}\mathrm{CO}_{2} \text { capture } \\
\text { efficiency }(\%)\end{array}$ & $\begin{array}{l}\text { Investment } \\
\text { cost (million } \\
\text { US\$(2000)) }\end{array}$ & $\begin{array}{l}\text { O\&M cost (million } \\
\text { US\$(2000)/year) }\end{array}$ \\
\hline Case 1 & 4.2 & 2.89 & 0.56 & 94 & 970 & 55 \\
Case 2 & 4.2 & 2.89 & 0.65 & 94 & 970 & 50 \\
Case 3 & 4.3 & 2.94 & 0.83 & 95 & 1070 & 60 \\
Ref. [1] & 3.4 & 1.86 & 0.054 & 87 & 430 & 26 \\
Ref. [2] & 4.5 & 1.40 & 0.038 & 100 & 430 & 24 \\
\hline
\end{tabular}

${ }^{a}$ The feedstock ratio is defined as: [the energy content (HHV basis) of feedstock input to the process]/[the energy content (HHV basis) of product (hydrogen)].

b The electricity output ratio is defined as: [the net electricity output]/[the energy content (HHV basis) of product (hydrogen)].

The second hydrogen-only reference system [2] is a membrane-based system similar to that of Case 2, with the exception that the hydrogen from the membrane reactor is not split into two streams (see Fig. 5).

Notice that, since part of the feedstock is used to produce electricity in the co-production systems, the efficiency of hydrogen production is smaller in the co-production systems as compared to the respective hydrogen-only production systems.

Table 2 shows the common set of assumptions used here to derive hydrogen production cost estimates. The hydrogen production cost was calculated using these assumptions, based on efficiency, capital cost and O\&M cost as given in Table 1.

As for the costs of $\mathrm{CO}_{2}$ disposal, under our assumptions, the $\mathrm{CO}_{2}$ that is separated from the plant is compressed to supercritical pressures for pipeline transportation. We include the costs of $\mathrm{CO}_{2}$ compression as well as $\mathrm{CO}_{2}$ capture into the plant investment costs. Following [10], it is assumed that

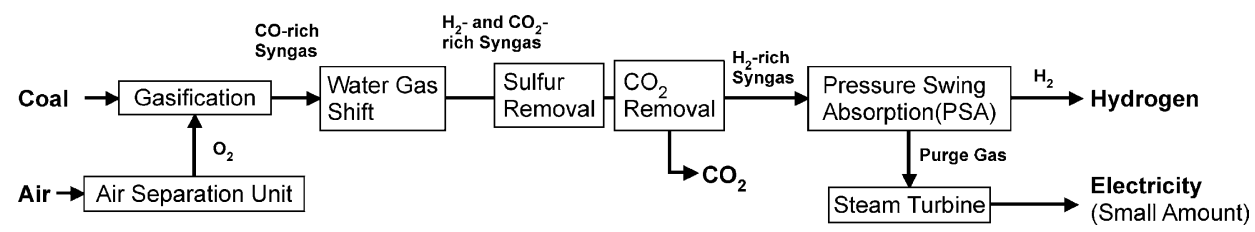

Fig. 4. Block flow diagram of a conventional system for hydrogen production from coal using a Pressure Swing Adsorption (PSA) unit with $\mathrm{CO}_{2}$ capture [1].

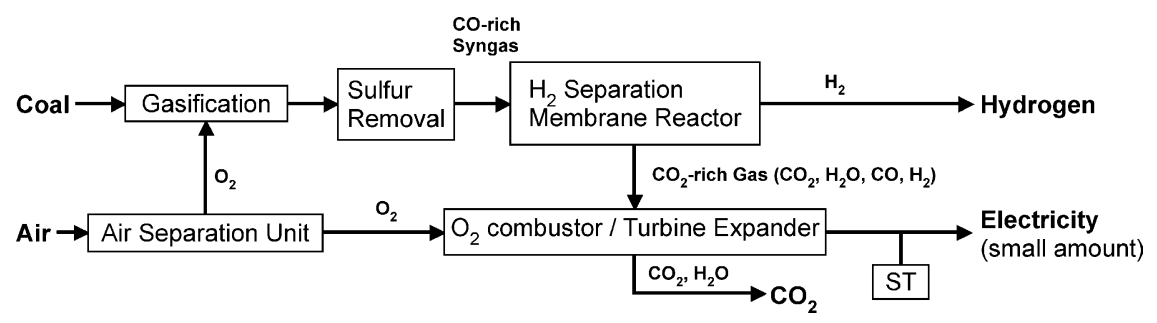

Fig. 5. Block flow diagram of a membrane-based system for hydrogen production from coal with $\mathrm{CO}_{2}$ capture [2]. 
Table 2

Assumptions for calculation of hydrogen production costs

Coal price

Annual capital charge rate

Capacity factor
$1.3 \mathrm{US} \$(2000) / \mathrm{GJ}$ (HHV basis)

0.15 annual interest rate $14 \%$, plant life 20 years

0.90 for gas-fired plants

0.80 for coal-fired plants

$5.0 \mathrm{US} \$(2000) / \mathrm{tCO}_{2}$

the costs of $\mathrm{CO}_{2}$ transport and storage are $5 \mathrm{US} \$ / \mathrm{tCO}_{2}$, which corresponds to a $100-\mathrm{km}$ pipeline and a 2-km deep injection well. This aggregate estimate is in line with the cost ranges reported by [22], who give 1-3 US\$/tCO 2 as a plausible range for costs of storing $\mathrm{CO}_{2}$ in deep saline aquifers or depleted oil/gas fields and a likely range of $1-3 \mathrm{US} \$ / \mathrm{tCO}_{2} / 100 \mathrm{~km}$ for transportation of captured $\mathrm{CO}_{2}$ from sources to reservoirs. It should be noticed that many uncertainties still exist regarding these figures.

In the co-production systems, hydrogen production costs are highly affected by the value at which coproduced electricity can be sold. In order to illustrate this dependence, we make some assumptions for the selling price of electricity co-produced with hydrogen. Following [9], these assumptions are based on the electricity generation costs of Natural Gas Combined Cycle (NGCC) and Integrated Gasification Combined Cycle (IGCC) power plants as described below.

This selling price of electricity depends on the price of the feedstock for electricity production. Fig. 6 presents the electricity generation costs for the NGCC and IGCC technologies (with and without carbon capture) as a function of the price of natural gas. ${ }^{3}$ The electricity generation costs from these reference gas-fired NGCC plants increase linearly as the price of natural gas increases, while those of coal-fired IGCC plants remain unchanged (it is assumed that coal prices remain constant at $1.3 \mathrm{US} \$ / \mathrm{GJ}$ ). As shown, NGCC power plants are more economic than IGCC plants for a wide range of gas prices. Under the assumptions here, without carbon capture, the electricity generation costs of NGCC plants reach the IGCC 'threshold' when the gas price raises above approximately 4.3 US\$/GJ. With carbon capture, the interception occurs at a lower price of approximately $3.5 \mathrm{US} \$ / \mathrm{GJ}$.

Here, we use the generation costs of this NGCC plant, which increases linearly with the gas price, as our assumption for the electricity price. However, if natural gas prices become high enough other electricity production technologies would become more attractive. Thus, on the rationale that the price at which electricity can be sold would correspond to that of the available lowest-cost plant, we have set a limit for this linear increase. This limit has been chosen as the 'threshold' value where NGCC generation costs become equal to those of a coal-fired IGCC power plant (see Fig. 6 above), provided that coal prices remain constant.

\footnotetext{
${ }^{3}$ Based on [23], investment costs, O\&M costs, thermal efficiencies and $\mathrm{CO}_{2}$ emissions are taken as follows:

NGCC: 502 US\$/kW, 0.26 cents/kWh, 53.6\% (HHV basis), $338 \mathrm{~kg}-\mathrm{CO}_{2} / \mathrm{MWh}$

NGCC w/CO ${ }_{2}: 943 \mathrm{US} \$ / \mathrm{kW}, 0.64$ cents/kWh, $43.3 \%$ (HHV basis), $40 \mathrm{~kg}-\mathrm{CO}_{2} / \mathrm{MWh}$

IGCC: $1266 \mathrm{US} \$ / \mathrm{kW}, 0.65$ cents $/ \mathrm{kWh}, 43.1 \%$ (HHV basis), $718 \mathrm{~kg}-\mathrm{CO}_{2} / \mathrm{MWh}$

IGCC w/CO $2: 1648 \mathrm{US} \$ / \mathrm{kW}, 0.78$ cents $/ \mathrm{kWh}, 37.0 \%$ (HHV basis), $73 \mathrm{~kg}-\mathrm{CO}_{2} / \mathrm{MWh}$
}

For all plants, it is assumed that the annual capital charge rate is 0.15 , capacity factor 0.8 , coal price 1.3 US $\$ / G J$ (HHV basis) and $\mathrm{CO}_{2}$ transport and storage cost $5 \mathrm{US} \$ / \mathrm{tCO}_{2}$. 


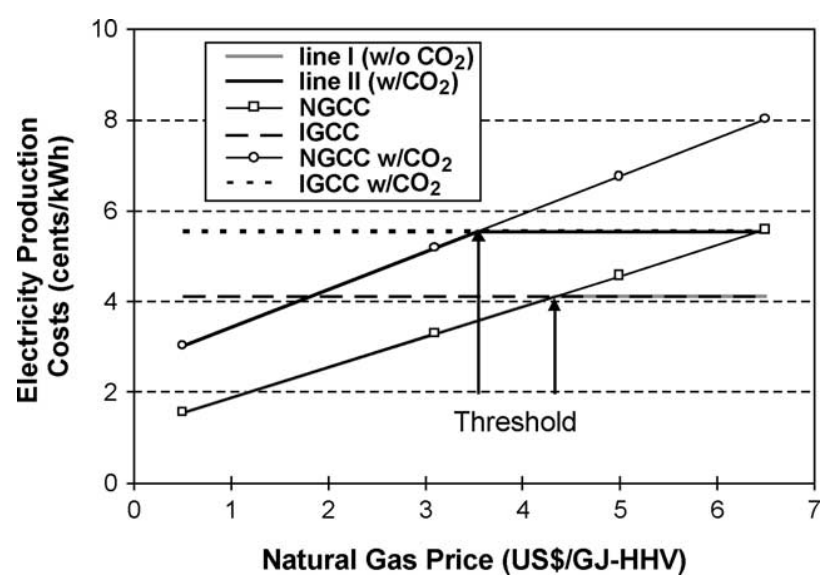

Fig. 6. Assumed selling price of co-produced electricity. This graph shows the relationship of electricity production costs to natural gas price, for a NGCC and a IGCC power plant with and without $\mathrm{CO}_{2}$ capture, at the coal price of 1.3 US\$/GJ. In estimation of co-production systems without $\mathrm{CO}_{2}$ capture, it is assumed that co-produced electricity is sold at the price which the Line I gives as a function of natural gas price. For the case with $\mathrm{CO}_{2}$ capture, the Line II is used.

In Fig. 6, the resulting relationships representing the dependence of electricity generation costs on the prices of natural gas are labeled as 'Line I' for the case without carbon capture and 'Line II' for the case with carbon capture. Here, we examine only the cases with carbon capture (Line II).

On the basis of these assumptions, it is equivalent to illustrate the dependence of the production costs of hydrogen on the price of natural gas, which on its turn determines the price at which the co-produced electricity can be sold. Fig. 7 presents the sensitivity of the production costs of hydrogen to the price of natural gas.

In the co-production cases (Cases 1-3), hydrogen production costs are strongly influenced by the electricity-selling price. In the linearly increasing region, with higher costs of natural gas, the electricity generation costs increase and, therefore, the credits for sales of the co-product electricity in the joint production facility become larger. Consequently, the production costs of hydrogen are linearly reduced.

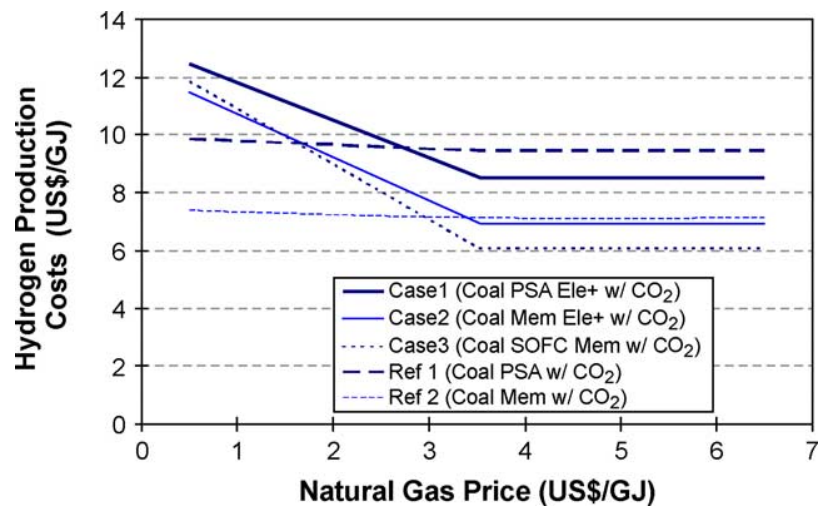

Fig. 7. Estimated hydrogen production costs in coal-based co-production plants as a function of natural gas price. The cases with only hydrogen production are also shown for comparison $[1,2]$. 
Once the natural-gas price reaches the level where the IGCC plant becomes more competitive than the NGCC plant, the production costs of hydrogen become insensitive to further increases in the natural gas price.

The systems with only hydrogen production are also shown for comparison (cases Refs. [1,2]). In these cases, however, the amount of electricity produced and sold to the network is too small to produce significant changes in the hydrogen production costs.

The hydrogen production costs in the co-production schemes based on membrane reactors (Case 2 and Case 3) are considerably lower than those in the co-production scheme based in the conventional PSA unit (Case 1). In addition, in these illustrative calculations, the co-production system that includes both a membrane-reactor and an SOFC 'topping cycle' (Case 3) appears to have the largest potential to achieve costs reductions in the production of hydrogen. It should be noticed, however, that some sources in the literature [24] attribute a much lower potential for cost reductions to membrane-based hydrogen + electricity co-production schemes than [9], which is the source of the figures used in this paper.

Fig. 7 also suggests that co-production systems might be attractive, as compared to the respective hydrogen-only production systems, when the price of natural gas rises above a given level. Still, under the assumptions made here, the benefits of selling the co-product electricity will increase only up to the point where the above-mentioned 'threshold' for the price of natural gas, and therefore the electricity price, is reached.

However, the magnitude of the reduction of hydrogen production costs in the co-production mode relative to the respective hydrogen-only system differs significantly between the alternative configurations. The benefits of co-production in Case 2, i.e. the membrane-based system, appear small, while those of Case 1 are larger.

In order to understand this behavior it is important to compare the configurations in Case 1 and Case 2 (describe in Table 1 above) and the respective hydrogen-only systems [1,2]. It can be noticed that the advanced HSMR-based co-production system (Case 2) has a higher electricity-to- $\mathrm{H}_{2}$ ratio than the conventional PSA-based co-production system (Case 1). However, the reduction of hydrogenproduction efficiency relative to the respective hydrogen-only production system is lower for the PSAbased system (Case 1) than for the HSMR-based system (Case 2). For the sake of clarity, these two aspects are illustrated in the values summarized in Table 3.

The implications of these two factors are as follows. On the one hand, a higher electricity-to- $\mathrm{H}_{2}$ ratio results in a faster reduction of the $\mathrm{H}_{2}$ production costs as the selling price of the co-product electricity (reflected by the price of natural gas in our analysis) is increased. This is because a larger amount of electricity is produced and sold and, thus, credits due to sales of the co-product electricity are larger per

Table 3

Comparison of feedstock ratio and electricity-to- $\mathrm{H}_{2}$ ratio for the co-production systems in Case 1 and Case 2 and their respective hydrogen-only production systems

\begin{tabular}{|c|c|c|c|c|}
\hline & \multicolumn{2}{|l|}{$\mathrm{H}_{2}$-only } & \multicolumn{2}{|c|}{$\mathrm{H}_{2}$ and electricity co-production } \\
\hline & PSA [1] & HSMR [2] & PSA (Case 1) & HSMR (Case 2) \\
\hline Feedstock ratio ${ }^{\mathrm{a}}\left(\mathrm{GJ} / \mathrm{GJ} \mathrm{H}_{2}\right)$ & 1.69 & 1.40 & 2.89 & 2.89 \\
\hline Electricity output ratio $^{\mathrm{a}}\left(\mathrm{GJ} / \mathrm{GJ} \mathrm{H}_{2}\right.$ ) & 0.037 & 0.038 & 0.56 & 0.65 \\
\hline
\end{tabular}

\footnotetext{
${ }^{\text {a }}$ For a definition, see notes in Table 1.
} 
unit of hydrogen in Case 2 as compared to Case 1. That is, as shown in the Fig. 7, the downward slope of the curve in the co-production Case 2 is higher than in Case 1.

On the other hand, a lower relative reduction of hydrogen-production efficiency brings a smaller increase in hydrogen production costs. Now, the relative reduction of hydrogen-production efficiency in Case 1 is lower than in Case 2. Thus, the difference between the hydrogen production costs of Case 1 and its respective $\mathrm{H}_{2}$-only case [1] at low natural gas prices is smaller than between Case 2 and its respective $\mathrm{H}_{2}$-only case [2]. Therefore, and despite the fact that its downward slope is smaller, the price of natural gas (i.e. the electricity-selling price), at which the hydrogen production costs becomes lower than those of the hydrogen-only case, is lower in Case 1 than Case 2. Since the natural-gas price 'threshold' at which the reduction in hydrogen production costs ceases is the same for both cases, the benefits of coproduction are larger for Case 1.

\section{Co-production of liquid fuels and electricity from coal}

An alternative poly-generation strategy based on coal gasification systems is the co-production of electricity and synthetic liquid fuels. Increasing environmental concerns leading to the implementation of more stringent specifications for fuels, especially in the transport sector, could stimulate liquid synfuels penetration. In addition, liquid synthetic fuels production from indigenous resources, such as coal, could be an attractive option for countries reluctant to excessively rely on imported oil, which has widely-known associated geopolitical instabilities. Thus, their share of the global final-energy mix could augment substantially in the future.

A number of synthetic fuels have been highlighted as alternatives to the currently dominating oil products in the transportation system. Among others, ethanol, methanol, di-methyl-ether (DME), FischerTropsch (F-T) liquids (diesel, gasoline) and hydrogen have been considered as potential candidates. While hydrogen is regarded as an attractive option for the long term, clean liquid synfuels could have applications in a nearer time horizon. They could contribute in addressing air pollution problems resulting from the growing use of oil products in the transportation sector [7,13]. Also, they could play a role in reducing greenhouse gas emissions. On the one hand, they can be used in highly efficient end-use technologies such as advanced internal combustion engines, hybrid vehicles and, later on, fuel cells. On the other hand, syngas-based production of liquid synthetic fuels could enable $\mathrm{CO}_{2}$ capture and storage.

Clean liquid synfuels could be instrumental in a transition of the global transportation sector, away from its today's heavy reliance on oil products, towards a more diversified, cleaner and balanced mix of energy carriers meeting mobility and freight needs. Moreover, liquid synfuels could operate as 'bridging' energy carriers in a long-term transition towards an energy system where hydrogen and electricity play the main roles.

As mentioned above, the co-production of electricity and liquid synfuels could have advantages in comparison to synfuel-dedicated plants. In addition, since both electricity and liquid synfuels would be more compatible with the existing infrastructure than, for instance, hydrogen, this scheme could provide an attractive strategy for the early introduction of 'energyplexes' into the marketplace. In the long term, if demand for hydrogen grows, these facilities could be adapted to accommodate hydrogen as an additional product or shift to a scheme where only hydrogen and electricity are co-produced. 


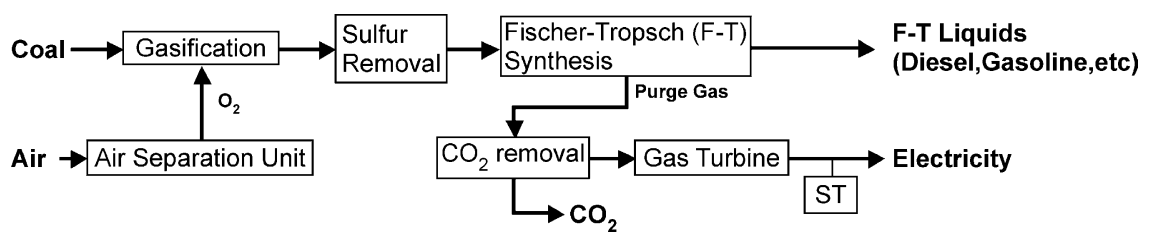

Fig. 8. Co-production of F-T liquids and electricity from coal with $\mathrm{CO}_{2}$ capture. For the system without $\mathrm{CO}_{2}$ capture, the block of $\mathrm{CO}_{2}$ removal is to be omitted.

Here, we highlight two illustrative configurations. The first system considered here is a coal gasification plant that co-produces electricity and Fischer-Tropsch (F-T) liquids. The second system under examination here co-produces electricity and methanol.

\subsection{Co-production of electricity and Fischer-Tropsch liquids}

Here, we highlight an illustrative configuration, namely a coal gasification plant that co-produces electricity and Fischer-Tropsch (F-T) liquids. The so-called Fischer-Tropsch synthesis reactor allows converting syngas into a mixture of various paraffinic and olefinic hydrocarbons. Among others, clean diesel and gasoline can be obtained, which do not contain sulfur or nitrogen, have very low contents of aromatics and exhibit a high Cetane number [5]. ${ }^{4}$

Although this technology has been known for several decades, commercial applications have been limited so far (mainly in South Africa [25,26]). However, clean F-T liquids could offer possibilities for compliance with stricter environmental rules in the transportation sector, already being implemented today or to be enforced in the short term. In particular, they could be used as a blending stock to produce low-sulfur gasoline and diesel, which are necessary for the adequate functioning of the emission control technologies that could reduce $\mathrm{NO}_{x}$ emissions from current vehicles to very low levels. In the medium term, F-T liquids could play an important 'bridging' role in a transition towards cleaner and more convenient transportation fuels and technologies. Specifically, they could enable a more efficient and environmentally compatible use of advanced internal combustion engines.

In addition, F-T synthesis can produce a number of different chemical compounds, some of which may have an important value in the market, although the size of those markets would probably not be large. Although they are not considered here, this feature provides the possibility of exploiting synergies between fuels and chemicals, which could contribute in making co-production strategies more attractive [25].

In a co-production mode, the purge gas from the $\mathrm{F}-\mathrm{T}$ synthesis reactor, which is the gas stream nonreacted in the $\mathrm{F}-\mathrm{T}$ process, can be used as a supplementary input to the electricity generation process, thus increasing the overall efficiency [5]. Also, the co-production scheme facilitates the capture of $\mathrm{CO}_{2}$ as compared to an F-T-only process.

The technical and economic characteristics of the process illustrated here have been adopted from [12]. As before, we consider cases with and without carbon capture. Fig. 8 presents the block flow

\footnotetext{
${ }^{4}$ The Cetane number measures the ignition quality of a diesel fuel. A higher Cetane number implies the higher capacity of a fuel to auto-ignite.
} 
Table 4

Summary of co-production systems of F-T liquids and electricity from coal

\begin{tabular}{|c|c|c|c|c|c|c|}
\hline & $\begin{array}{l}\text { F-T liquid } \\
\text { capacity } \\
\text { (TJ/day) }\end{array}$ & $\begin{array}{l}\text { Feedstock } \\
\text { ratio }^{\mathrm{a}} \\
(\mathrm{GJ} / \mathrm{GJ}-\mathrm{F}-\mathrm{T})\end{array}$ & $\begin{array}{l}\text { Electricity } \\
\text { output ratio }^{\mathrm{a}} \\
\left(\mathrm{GJ}_{\mathrm{e}} / \mathrm{GJ}-\mathrm{F}-\mathrm{T}\right)\end{array}$ & $\begin{array}{l}\mathrm{CO}_{2} \text { capture } \\
\text { efficiency }(\%)\end{array}$ & $\begin{array}{l}\text { Investment } \\
\text { cost (million } \\
\text { US\$) }\end{array}$ & $\begin{array}{l}\text { O\&M cost } \\
\text { (million US\$/ } \\
\text { year) }\end{array}$ \\
\hline $\begin{array}{l}\text { Without } \mathrm{CO}_{2} \\
\text { capture }\end{array}$ & 190 & 2.2 & 0.32 & 0 & 2200 & 118 \\
\hline $\begin{array}{l}\text { With } \mathrm{CO}_{2} \\
\text { capture }\end{array}$ & 190 & 2.2 & 0.23 & 90 & 2290 & 123 \\
\hline
\end{tabular}

${ }^{\mathrm{a}}$ For a definition, see notes in Table 1.

diagram of the F-T liquids co-production system, and Table 4 summarizes performances and costs used for this analysis.

The purge gas from the F-T unit, which contains the unconverted syngas, methane, ethane, ethylene, and carbon dioxide, is sent to a gas turbine combustor, followed by the heat recovery steam generator. For the $\mathrm{CO}_{2}$ capture case, the carbon dioxide is removed using an amine system from the purge gas before it is combusted. Approximately $58 \%$ of the carbon dioxide in the feedstock is captured, $6 \%$ is emitted to the atmosphere and about $36 \%$ in the F-T product.

As in the hydrogen-and-electricity case, the economics of F-T liquid fuels production in the coproduction plant are significantly affected by the price at which the co-product electricity can be sold to the network. Assumptions for the price of electricity in this case are the same as described above for the hydrogen and electricity co-production case, following [12]. Fig. 9 presents the sensitivity of the production costs of $\mathrm{F}-\mathrm{T}$ liquids to the price of natural gas. Cases with and without $\mathrm{CO}_{2}$ capture are shown for two different levels of coal prices. For reference purposes, the production costs of F-T liquids from coal with no co-product are also shown. ${ }^{5}$

The production costs of F-T liquids were calculated on the assumptions in Table 2. As before, with higher prices of natural gas, the price at which the co-product electricity can be sold becomes larger and, therefore, the production costs of F-T liquids are reduced. Once the natural gas price reaches the 'threshold' value, the production costs of F-T liquids become insensitive to further increases in the price of natural gas. As discussed in the assumptions above, these 'threshold' prices are different in the cases with and without capture of $\mathrm{CO}_{2} \cdot{ }^{6}$ Clearly, in the case without capture of $\mathrm{CO}_{2}$ a lower 'floor' cost of F-T liquids is reached. The incorporation of the capture system, however, does not increase their costs significantly. Also, as expected, lower costs of coal drive to lower production costs of F-T liquids.

The production costs and the $\mathrm{CO}_{2}$ emissions of a co-production facility are lower than those of a facility that only produces $\mathrm{F}-\mathrm{T}$ liquids. But, even in a co-production facility where credits are received for the electricity being sold, F-T liquids from coal would most likely be considerably more expensive

\footnotetext{
${ }^{5}$ Based on [26], investment cost of 3245 million US\$ and thermal efficiency of $63.6 \%$ (HHV basis) are assumed for a plant of $290 \mathrm{TJ}$ of F-T liquids per day. It is assumed that O\&M cost is $4 \%$ of investment/year, coal price is 1.3 US\$/GJ, the annual capital charge rate is 0.15 , capacity factor 0.8 and $\mathrm{CO}_{2}$ disposal cost $5 \mathrm{US} \$ / \mathrm{tCO}_{2}$.

${ }^{6}$ As shown in Fig. 6, for the case without $\mathrm{CO}_{2}$ capture the cost of electricity generation of power plants without $\mathrm{CO}_{2}$ capture are used. For the case with $\mathrm{CO}_{2}$ capture the cost of electricity generation of power plants with $\mathrm{CO}_{2}$ capture are used.
} 


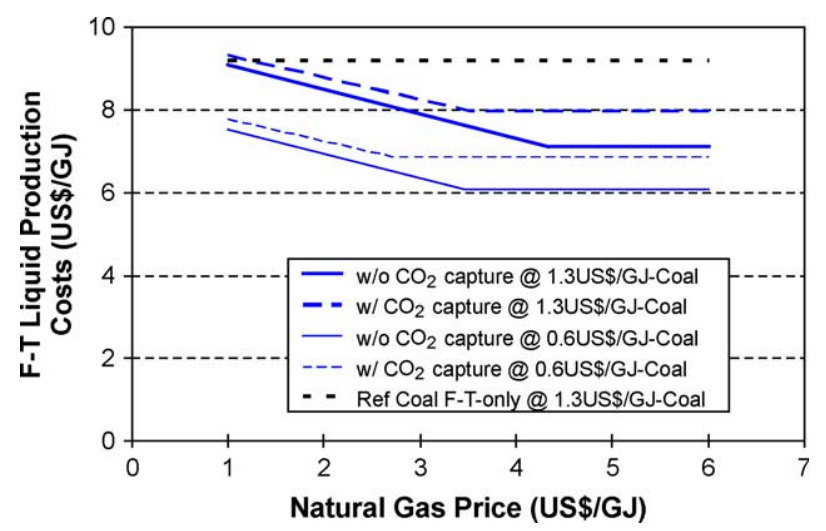

Fig. 9. Estimated production costs of F-T liquids in a coal-fired co-production plant as a function of natural gas price. Cases with and without $\mathrm{CO}_{2}$ capture are shown for two different levels of coal prices, 1.3 and 0.6 US\$/GJ. For reference purposes, the production costs of F-T liquids from coal with no co-product are also shown for a coal price of 1.3 US\$/GJ.

than petroleum diesel ${ }^{7}$ or F-T liquids from low-price natural gas. ${ }^{8}$ Moreover, without $\mathrm{CO}_{2}$ capture, their production is much more carbon-intensive.

With $\mathrm{CO}_{2}$ capture, the costs of the $\mathrm{F}-\mathrm{T}$ liquids are increased but not significantly and the $\mathrm{CO}_{2}$ emissions would lie in the range of those of petroleum diesel. The introduction of F-T liquids from coal, at least with today's efficiencies, would not drive to a reduction in carbon emissions as compared to oil products or natural-gas-based $\mathrm{F}-\mathrm{T}$ liquids. Thus, the incorporation of $\mathrm{CO}_{2}$ capture and storage appears an important prerequisite if the production of these energy carriers from coal is to contribute to the mitigation of $\mathrm{CO}_{2}$ emissions.

Nonetheless, F-T liquids are premium products, without sulfur or nitrogen contents, that could have attractive applications, initially as blending stock for gasoline and diesel to comply with more stringent environmental regulations and, later on, as high-quality fuels that could enable the use of advanced engines. As mentioned above, they could contribute in reducing the sulfur content of transportation fuels and, subsequently, in enabling the operation of the technologies necessary for the reduction of $\mathrm{NO}_{x}$ emissions from mobile sources, thus bringing air quality benefits. Due to these characteristics, some automakers have started to pursue activities in this direction [29,30], although mainly concentrating on F-T liquids from natural gas.

\footnotetext{
${ }^{7}$ It is assumed the price of diesel from crude oil is 0.18 US\$/1 as an average untaxed retail price for November in 1998 [27]. This is equivalent to $4.7 \mathrm{US} \$ / \mathrm{GJ}$.

${ }^{8}$ Based on [28], investment costs, O\&M costs, thermal efficiencies and $\mathrm{CO}_{2}$ emissions of $\mathrm{F}-\mathrm{T}$ liquid plant from natural gas, which produces $57 \mathrm{TJ}$ of F-T liquids per day, are assumed as follows:
}

NG F-T: 346 million US\$, 72.1 million US\$/year, 53.2\% (HHV basis), $20.2 \mathrm{tC} / \mathrm{h}$

NG F-T w/CO $\mathrm{CO}_{2}: 389$ million US\$, 83.1 million US\$/year, 52.6\% (HHV basis), $6.0 \mathrm{tC} / \mathrm{h}$

It is assumed that the price of remote natural gas is $0.5 \mathrm{US} \$ / \mathrm{GJ}$, the annual capital charge rate is 0.15 , capacity factor 0.9 and $\mathrm{CO}_{2}$ disposal cost $5 \mathrm{US} \$ / \mathrm{t} \mathrm{CO}_{2}$. Under these assumptions, $\mathrm{F}-\mathrm{T}$ production costs of $4.6 \mathrm{US} \$ / \mathrm{GJ}$ (without $\mathrm{CO}_{2}$ capture) and 5.0 US\$/GJ (with $\mathrm{CO}_{2}$ capture) can be obtained. 
Still, if cheap coal is available and credits for cleanliness of the F-T products are accounted for, coalderived F-T liquids could be an interesting alternative in regions where natural gas is not available or expensive or where geopolitical reasons preclude an excessive reliance on imported fuels. In supplying such market segment and possible larger markets that could emerge later on, a coal-based co-production scheme incorporating capture of $\mathrm{CO}_{2}$ as illustrated here could be more attractive than an $\mathrm{F}-\mathrm{T}$-only production process.

\subsection{Co-production of electricity and methanol}

An alternative system based on syngas allows the co-production of electricity and methanol, which can be used either as a chemical feedstock or as an energy carrier. As an energy carrier, methanol has a number of potential applications. One attractive possibility is its use in fuel cells for mobile applications. Methanol can be easily reformed into hydrogen and is more easily stored and transported than hydrogen [7,31]. Also, using methanol in fuel cells would be more efficient and more environmentally benign than its application in internal combustion engines. However, concerns about its toxicity risks still have to be adequately addressed.

Co-producing electricity and methanol could contribute to enhancing the economics of both products. Here, we illustrate a system configuration combining the so-called Liquid Phase Methanol Process $\left(\mathrm{LPMEOH}^{\mathrm{TM}}\right)$, a relatively novel process being pursued by the US Department of Energy and several industrial partners [32,33], and an IGCC power plant.

The LPMEOH ${ }^{\mathrm{TM}}$ process, which is currently in the demonstration stage, converts synthesis gas into methanol. This process can reach higher synthesis gas conversion levels in a single pass through the reactor and has lower purification costs than a conventional gas phase methanol production technology. Also, it allows producing high-quality methanol from a wider range of syngas compositions and specifically from syngas mixtures rich in carbon monoxide.

An integrated system, combining an IGCC power plant and a LPMEOH ${ }^{\mathrm{TM}}$ reactor, provides additional flexibility and allows higher conversion efficiencies. It also opens the possibility for profiting from electric load variations by performing the bulk production of methanol during off-peak periods, thus allowing the gasifier to operate at full load.

The technical and economic characteristics of the process considered here are based on the analysis reported by [32]. We consider only the case without $\mathrm{CO}_{2}$ capture since no economic data of a methanol co-production plant with $\mathrm{CO}_{2}$ capture could be found in the literature available to the authors. Fig. 10 presents the block flow diagram of the methanol/electricity co-production system, and Table 5 summarizes the performance and costs of the co-production facility. For comparison, the characteristics of the methanol-only production system based on a conventional gas phase reactor are presented as reference.

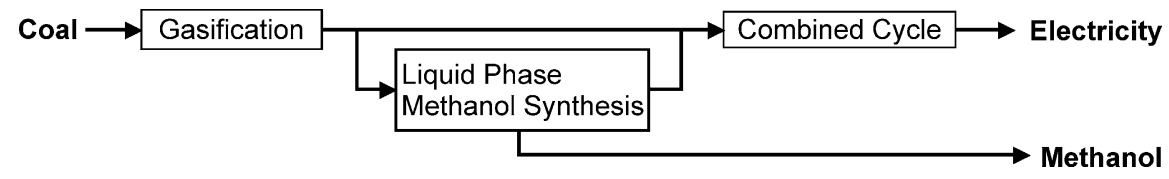

Fig. 10. An integrated system combining an IGCC power plant and a $\mathrm{LPMEOH}^{\mathrm{TM}}$ reactor. 
Table 5

Summary of co-production systems of methanol and electricity from coal

\begin{tabular}{llllll}
\hline & $\begin{array}{l}\text { Methanol } \\
\text { capacity (GJ/h) }\end{array}$ & $\begin{array}{l}\text { Electricity output } \\
\text { ratio }^{\mathrm{a}}(\mathrm{GJ} / \mathrm{GJ}- \\
\text { methanol) }\end{array}$ & $\begin{array}{l}\text { Feedstock ratio } \\
(\mathrm{GJ} / \mathrm{GJ}-\text { methanol) }\end{array}$ & $\begin{array}{l}\text { Investment cost }^{\mathrm{b}} \\
(\text { million US\$) }\end{array}$ & $\begin{array}{l}\text { O\&M cost }^{\mathrm{b}} \\
(\mathrm{million} \text { US\$/ } \\
\text { year) }\end{array}$ \\
\hline Co-production & 430 & 2.9 & 8.1 & 550 & 13.7 \\
Methanol-only & 430 & 0.0 & 1.5 & 164 & 5.1 \\
\hline
\end{tabular}

${ }^{\text {a }}$ For a definition, see notes on Table 1.

b The investment costs and O\&M costs for methanol synthesis are based on Air Products and Chemicals (1998). Those for facilities related to coal gasification and combined cycle on EPRI (2000), assuming scale factor is 0.7.

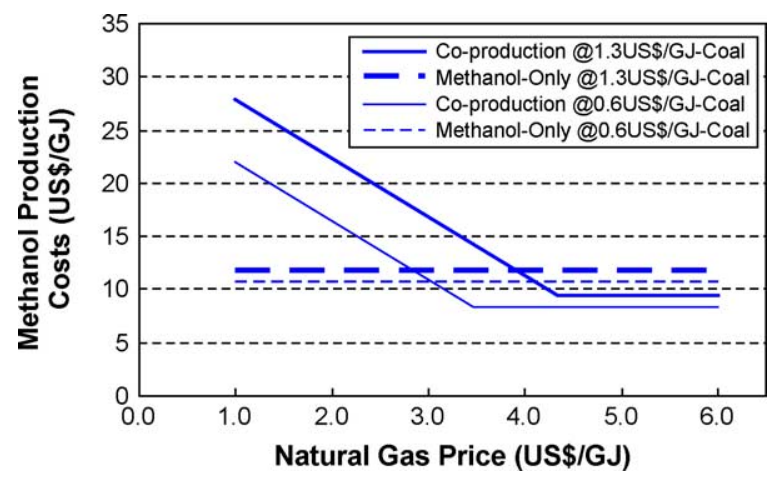

Fig. 11. Methanol production costs of co-production plant and methanol-only production plant from coal as a function of natural gas price. The results for two different levels of coal prices, 1.3 and $0.6 \mathrm{US} \$ / \mathrm{GJ}$, are shown.

Here, we illustrate how production cost of methanol in the co-production plant is affected by the price at which the co-product electricity is sold. As before, the assumptions on the selling price of electricity are those described in Section 3 above.

Fig. 11 depicts the dependence of the production costs of methanol on the price of natural gas, which, under our assumptions, determines the selling price of the co-produced electricity. Methanol production costs were calculated on the assumptions in Table 2, except for prices of electricity.

As before, with higher prices of natural gas, the price at which the co-product electricity can be sold becomes larger and, therefore, the production costs of methanol are reduced. Once the natural gas price reaches the 'threshold' price, the production costs of methanol become insensitive to further increases in the natural gas price and reach 'floor' values.

According to our assumptions, the coal price determines the 'floor' that the methanol production cost can reach. As expected, with a lower price for the coal feedstock the methanol production cost is lower and, of course, a lower 'floor' cost can be achieved. However, the 'floor' cost is also reached at lower natural gas prices because the 'threshold' value for the price at which the co-product electricity can be sold also becomes lower. ${ }^{9}$

\footnotetext{
${ }^{9}$ Here, the reader should bear in mind the assumptions described in Section 3.
} 
Methanol from coal might be competitive with methanol from natural gas depending on the relative prices of natural gas and coal, but it still appears to be more expensive than petroleum diesel. Moreover, its production is more carbon-intensive. Thus, the introduction of methanol from coal without $\mathrm{CO}_{2}$ capture would most likely not lead to a reduction in carbon emissions as compared to oil products or natural gas based methanol. $\mathrm{CO}_{2}$ capture, again, appears to be an important prerequisite if the production of these energy carriers from coal is to contribute to mitigation of $\mathrm{CO}_{2}$ emissions.

\section{Conclusions}

This paper has examined the production of hydrogen, electricity and liquid fuels using a coal gasification process. This process could constitute a key building block of integrated energy systems, also known as 'energyplexes', based on the production of synthesis gas (syngas) and capable of having multiple products and use several feedstocks.

We have explored three co-production strategies based on coal gasification, namely hydrogen and electricity, F-T liquids and electricity and methanol and electricity. Our assessment illustrates how co-production schemes may improve the economics of hydrogen, F-T liquids or methanol production, respectively, if the co-product electricity is sold to the network. Our results suggest that co-production schemes might become attractive compared to the systems with no coproduct electricity in the circumstance that the selling price of electricity exceeds a given 'threshold' level.

Using these examples we have highlighted the important role that integrated energy systems, enabling poly-generation strategies, may play in the long run in the global energy supply system. Specifically, we emphasize the role of synthesis gas (or syngas) as a key energy carrier for a multifuel, multi-product system based on carbonaceous feedstocks. On the one hand, syngas can be obtained not only from natural gas but also from solid energy carriers like coal and biomass thus allowing their conversion into higher quality, cleaner and more flexible energy carriers. Since the different synthesis gas production systems are similar, or at least compatible to some extent, this could facilitate the introduction of multi-fuel systems, provided technical issues about the quality and variety of feedstocks can be overcome. On the other hand, syngas production allows for a wide mix of products, i.e. electricity, hydrogen, di-methyl-ether (DME), chemicals, heat, $\mathrm{CO}_{2}$ among others.

Co-production, also known as poly-generation, strategies may contribute to improve the economics of the system and exploit potential synergies between the constituent processes. Moreover, in multiplying the potential sources of profit and the market segments that can be supplied, they could increase the adaptability and robustness of energy-services companies in the marketplace. However, the technical feasibility and economic viability of poly-generation schemes have to be examined carefully on a caseby-case basis and an adequate assessment of the existence of markets for excess co-products has to be conducted.

From today's perspective, the most plausible co-production schemes could be those of electricity and liquid fuels rather than hydrogen. Thus, it is important to place the different co-production schemes as components of an evolving time-stepped strategy for the introduction of co-production systems in the long term. Some co-production schemes (e.g. electricity and F-T liquids) could be attractive in the short 
term. In the medium term, electricity and methanol could become an interesting option. In the long term, electricity and hydrogen could be a promising alternative. Thus, it becomes important to examine the potential and timing of the different configurations in different stages of a transition towards a more sustainable energy system in the long run.

The role of the different co-production schemes could be well illustrated using the example of the transportation sector. Today, production of F-T liquids could be attractive as a blending stock to obtain gasoline and diesel with lower polluting levels that would power advanced and cleaner internal combustion engines. In the medium term, as more advanced technologies such as fuel cells are introduced, methanol could become attractive and facilitate their introduction. On-board reforming of methanol could help to overcome the problems posed by the lack of hydrogen production and delivery systems. Methanol could then play the role of a transition energy carrier. In the very long term, if a 'hydrogen + electricity' economy develops and hydrogen delivery infrastructure is deployed, fuel cell vehicles could be powered directly by hydrogen.

Poly-generation strategies could be launched with today's technologies [16]. Nonetheless, several of the technologies that would make the concept of 'energyplexes' operational, particularly when including hydrogen production and/or carbon capture and storage, are options for the long term, which still face a number of technical and economic barriers. Thus, a number of actions are still necessary to materialize the potential of these technologies and stimulate their diffusion at the global level. Among others, a number of R\&D needs have yet to be addressed both in the development of specific processes and components and their integration if the potential for higher efficiency, lower production costs and reduced environmental impacts is to be realized.

In addition, demonstration and deployment (D\&D) programs are necessary. While integrated energy systems incorporating carbon capture are still a long-term goal, a number of component technologies are already operational. In several cases, such as the gasification technologies, actions are required to accelerate their diffusion beyond their current niche markets or ensure that expertise in other (e.g. chemical sector) industries is transferred to energy-services companies. However, the industrial sector, and energy-services companies in particular, could perceive these technologies as (financially) risky and, therefore, may be reluctant to conduct the necessary research, development, demonstration and deployment activities (summarized as RD3). Therefore, government intervention is required both in conducting key long-term $R \& D$ activities and in setting up partnerships with the industry for the demonstration and deployment of these technologies.

\section{Acknowledgements}

We would like to express our appreciation to the Tokyo Electric Power Company (TEPCO) for their continued funding of this collaborative study. We would also like to thank Leo Schrattenholzer, leader of the Environmentally Compatible Energy Strategies Program at IIASA, and Takashi Okano, Research Group Leader of the Corporate Planning Department at TEPCO, for their support and useful comments and to Pat Wagner for her editorial assistance. The comments of two anonymous referees are highly appreciated. 


\section{References}

[1] DOE (US Department of Energy). Clean energy plants for the 21st century. Vision 21 program plan. Washington, DC, USA: Federal Energy Technology Center, Office of Fossil Energy, US Department of Energy; 1999a. p. 36.

[2] Williams RH, Bunn M, Consonni S, Gunter W, Holloway S, Moore R, et al. Advanced energy supply technologies. In: World energy assessment: energy and the challenge of sustainability, chapter 8 Washington/New York, US: UNDP/WEC/UNDESA (United Nations Development Programme, World Energy Council, UN Department of Economic and Social Affairs); 2000 [ISBN: 92-1-126126-0].

[3] Ni W, Li Z, Yuan X. National energy futures analysis and energy security perspectives in China-strategic thinking on the energy issue in the 10th five-year plan (FYP). Paper presented to the workshop on East Asia energy futures, Beijing, June; 2000.

[4] Simbeck D. Cogeneration for $\mathrm{CO}_{2}$ reduction and poly-generation for $\mathrm{CO}_{2}$ sequestration. Paper presented at the first national conference on carbon sequestration. National Energy Technology Laboratory (NETL), US Department of Energy; 2001.

[5] NETL (National Energy Technology Laboratory). Coproduction of power, fuels and chemicals. Topical report \#21. September, 2001. National Energy Technology Laboratory, US Department of Energy. http://www.netl.doe.gov/ publications/others/topicals/topical21.pdf; 2001.

[6] IEA/CERT (International Energy Agency/Committee for Energy Research and Technology). Solutions for the 21st century. Zero emissions technologies for fossil fuels. Technology status report. Working party on fossil fuels. Paris, France: Committee on Energy Research and Technology, International Energy Agency; 2002.

[7] Williams RH. Toward zero emissions from coal in China. Energy Sustain Dev 2001;V(4):39-65.

[8] Basye L, Swaminathan S. Hydrogen production costs—a survey SENTECH, Inc., Report DOE/GO/10170-778. Maryland, US: US Department of Energy; 1997.

[9] Gray D, Tomlinson G. Hydrogen from coal. Mitretek technical paper. MTR 2002-31; 2002.

[10] Kreutz TG, Williams RH, Socolow RH, Chiesa P, Lozza G. Production of hydrogen and electricity from coal with $\mathrm{CO}_{2}$ capture. Paper presented to the sixth greenhouse gas control conference (GHGT-6), Kyoto, Japan; 2002.

[11] Parsons Group (Parsons Infrastructure and Technology Group Inc.). Hydrogen production facilities. Plant performance and cost comparisons. Final report prepared for the US Department of Energy, March; 2002.

[12] Gray D, Tomlinson G. Co-production of ultra-clean transportation fuels, hydrogen and electric power from coal. Mitretek technical paper. MTR 2001-43, 2001.

[13] Celik F, Larson E, Williams RH. Transportation fuel from coal with low $\mathrm{CO}_{2}$ emissions. Paper presented to the seventh international conference on greenhouse gas control technologies, Vancouver, Canada, September 5-9; 2004.

[14] Socolow R, editor. Fuels decarbonization and carbon sequestration: report of a workshop. PU/CEES report no 302. Princeton, NJ: Princeton University; 1997 [September].

[15] David J, Herzog H. The cost of carbon capture. Paper presented to the fifth international conference on greenhouse gas control technologies (GHGT-5), Cairns, Australia, August 13-16; 2000.

[16] Riahi K, Barreto L, Rao S, Rubin E. Long term perspectives for carbon capture technologies in power plants: scenarios for the 21st century. Final report to Carnegie Mellon University. Report 00-133 ECS. Laxenburg, Austria: International Institute for Applied Systems Analysis; 2003.

[17] Ogden J. Prospects for building a hydrogen energy infrastructure. Annu Rev Energy Env 1999;24:227-79.

[18] Barreto L, Makihira A, Riahi K. The hydrogen economy in the 21st century: a sustainable development scenario. Int J Hydrogen Energy 2003;28(3):267-84.

[19] Williams RH. Toward zero emissions for coal: roles for inorganic membranes. Proceedings of the international symposium towards zero emissions: the challenge for hydrocarbons. Rome, Italy: EniTecnologie; 1999 [March 11-13].

[20] Shah MM, Drnevich RF. Integrated ceramic membrane system for hydrogen production. Proceedings of the 2000 hydrogen program review. NREL/CP-570-28890; 2000.

[21] Audus $\mathrm{H}$, Jackson AJ. $\mathrm{CO}_{2}$ Abatement by the combustion of $\mathrm{H}_{2}$-rich fuels in gas turbines. Paper presented to the fifth international conference on greenhouse gas control technologies (GHGT-5), Cairns, Australia, August 13-16; 2000. 
[22] Freund P, Thambimuthu K, Davison J. Sequestering $\mathrm{CO}_{2}$. Chapter 6. In technology options for achieving significant greenhouse gas emissions reductions from energy over the long term. Paris, France: Committee for Energy Research and Technology (CERT), International Energy Agency (IEA); 2003 [Forthcoming].

[23] EPRI (The Electric Power Research Institute). Evaluation of innovative fossil fuel power plants with $\mathrm{CO}_{2}$ removal: interim report, December; 2000.

[24] Chiesa P, Kreutz T, Williams RH. Analysis of hydrogen and co-product electricity production from coal with near zero pollutant and $\mathrm{CO}_{2}$ emissions using an inorganic hydrogen separation membrane reactor. Paper presented at the second annual conference on carbon sequestration, Alexandria, VA, USA, May 5-8; 2003.

[25] Geertsema A. Gas to synfuels and chemicals. Paper presented to 17th world energy congress, Houston, Texas, September; 1998.

[26] Bechtel Corporation. Baseline design/economics for advanced Fischer-Tropsch technology. Final report prepared for the US Department of Energy, Federal Energy Technology Center, Bechtel Corporation, April; 1998.

[27] Metschies GP. Fuel price and taxation with comparative tables for 160 countries. Deutsche Gesellschaft für Technische Zusammenarbeit (GTZ) GmbH, May; 1999.

[28] Marsh G, Bates J, Haydock H, Hill N, Clark C, Freund P. Application of $\mathrm{CO}_{2}$ removal to the Fischer-Tropsch process to produce transport fuel. Paper presented to the sixth greenhouse gas control conference (GHGT-6), Kyoto, Japan; 2002.

[29] Snyder P, Russell B, Schubert P. The case for synthetic fuels: enabling technology for advanced engines. Syntroleum corporation. Paper presented to the conference clean fuels 2000 - the race to produce new fuels and engines, San Diego, CA, USA; 2000.

[30] Steiger W. SunFuel ${ }^{\circledR}$ —Strategie Basis nachhaltiger Mobilität (in German), Volkswagen AG, Wolfsburg, Germany; 2000.

[31] IEA/AFIS (International Energy Agency/Automotive Fuels Information Service). Automotive fuels for the future: the search for alternatives. Paris, France: International Energy Agency; 1999.

[32] Air Products and Chemicals. Economic analysis: LPMEOH process as an add-on to integrated gasification combinedcycle (IGCC) for co-production. Report prepared for the US Department of Energy; 1998.

[33] DOE (US Department of Energy). Commercial-scale demonstration of the liquid phase methanol (LPMEOH ${ }^{\mathrm{TM}}$ ) process. US Department of Energy, April; 1999c. 


\section{Additional copies}

Further copies of this IIASA Reprint are available online at www.iiasa.ac.at/Publications

Hard copies are also available for a small handling charge. Orders must include the publication number and should be sent to the Publications Department, International Institute for Applied Systems Analysis, A-2361 Laxenburg, Austria.

Telephone: +432236807

Telefax: +432236 71313

E-mail: publications@iiasa.ac.at 
International Institute for Applied Systems Analysis

Schlossplatz 1, A-2361 Laxenburg, Austria

Tel: +432236807 Fax: +43223671313

I I AS A www.iiasa.ac.at 